\title{
Experimental investigation of the late phase of spent fuel pool accidents
}

\section{Mihály Kunstár, Lajos Matus, Nóra Vér, Anna Pintér and Zoltán Hózer*}

KFKI Atomic Energy Research Institute

Hungarian Academy of Sciences

H-1525 Budapest, P.O. Box 49, Hungary

E-mail: kunstar@sunserv.kfki.hu

E-mail:matus@sunserv.kfki.hu

E-mail: nver@sunserv.kfki.hu

E-mail: csordas@sunsery.kfki.hu

E-mail: hozer@sunserv.kfki.hu

*Corresponding author

\section{Martin Steinbrück and Juri Stuckert}

Forschungszentrum Karlsruhe $\mathrm{GmbH}$ Institut für Materialforschung I (IMF I)

Herrmann von Helmholtzplatz 1

76344 Eggenstein/Leopoldshafen, Germany

E-mail: martin.steinbrueck@imf.fzk.de

E-mail: juri.stuckert@imf.fzk.de

\begin{abstract}
Experimental programmes have been carried out in order to investigate the behaviour of nuclear fuel components in high-temperature air atmosphere, which characterises the main conditions of the late phase of spent fuel pool accidents. The tests provided new data on the oxidation of zirconium cladding in different atmospheres, on the oxidation and release of ruthenium from fuel pellets and on the integral behaviour of fuel bundles. The integral test confirmed that water injection into the spent fuel storage pool is the right measure to terminate a severe accident.
\end{abstract}

Keywords: spent fuel storage pool; SFSP; zirconium cladding; oxidation kinetics; ruthenium oxidation and release; quench; VVER reactors.

Reference to this paper should be made as follows: Kunstár, M., Matus, L., Vér, N., Pintér, A., Hózer, Z., Steinbrück, M. and Stuckert, J. (2007) 'Experimental investigation of the late phase of spent fuel pool accidents', Int. J. Nuclear Energy Science and Technology, Vol. 3, No. 3, pp.287-301.

Biographical notes: Mihály Kunstár graduated in chemistry at the Eötvös Lóránd University, Budapest in 1978. He is a Research Scientist at the Hungarian Academy of Sciences KFKI Atomic Energy Research Institute, dealing with mass spectrometry, high-temperature interactions of reactor core materials, adsorption and desorption of uranium on reactor core materials, fission product release in highly oxidising atmosphere, and ruthenium oxidation and transport. 
Lajos Matus graduated in chemistry at the Eötvös Lóránd University, Budapest in 1957. He received his $\mathrm{PhD}$ in Reaction Kinetics in 1982. He is a Senior Research Scientist at the Hungarian Academy of Sciences KFKI Atomic Energy Research Institute. His main activities include investigations on stable isotope effects, enrichment of boron-10 isotopes, mass spectrometry, kinetics of gas phase reactions, studies on hydrogen uptake/release, and high-temperature interactions of reactor core materials.

Nóra Vér graduated as a Chemical Engineer at the Budapest University of Technology and Economics in 2003. She is a Research Scientist at the Hungarian Academy of Sciences KFKI Atomic Energy Research Institute, working in the area of high-temperature reactions of cladding materials and of ruthenium oxidation and release.

Anna Pintér graduated in physics at the József Attila University, Szeged in 1971. She received her Dr. Univ. degree in Physics in 1979 and PhD in Physics in 1997 at the József Attila University, Szeged. She has been a senior research scientist at the Hungarian Academy of Sciences KFKI Atomic Energy Research Institute since 1996. Her main field is materials science, and her professional experience includes scanning electron microscopy, electron beam microanalysis, image analysis and production of composite powders. Her main activities include investigations of various cladding materials, aerosols and samples of reactor vessel.

Zoltán Hózer graduated as a Nuclear Engineer at the Moscow Power Engineering Institute in 1984 . He received a Dr. Univ. degree in Fluid Mechanics at the Technical University of Budapest in 1988 and a $\mathrm{PhD}$ in Nuclear Techniques at the Budapest University of Technology and Economics in 2004. He is a Research Scientist at the Hungarian Academy of Sciences KFKI Atomic Energy Research Institute, working in the area of fuel and reactor materials experimental and analytical studies. His background includes two-phase flow modelling, simulator software development, fuel behaviour and severe accident analysis.

Martin Steinbrück holds an MSc and $\mathrm{PhD}$ in Solid State Chemistry from the University of Jena, Germany. He has been with Forschungszentrum Karlsruhe since 1991. He has been working in various topics within the Programme Nuclear Safety for 13 years and with the QUENCH group for 11 years. At present he is in charge of the FZK QUENCH programme and is leading an experimental group.

Juri Stuckert graduated in physics at the University of Nischni Nowgorod, Russia, in 1980 and received a PhD in Thermodynamics at the Academy of Sciences, Moscow, in 2003. He is a Senior Research Scientist at the Institute for Materials Research of FZK. He has been working on investigations of reactor materials since 1986. Since 1997 he has been working at the nuclear safety programme of FZK, particularly in the QUENCH experimental project. His background includes investigation of reactor material interaction at high temperatures and severe accident analysis. 


\section{Introduction}

The numerical analysis of severe Spent Fuel Storage Pool (SFSP) accidents indicated missing knowledge on some specific phenomena. Most of the questions were related to the late phase of the accidents that can take place in the air atmosphere after boiling and evaporation of the coolant. In order to provide data for numerical model developments and validation, high-temperature experiments have been carried out under conditions typical for the late phase of severe SFSP accidents. The current work concentrated on fuel bundle degradation, reactions of cladding materials and fission product release at high temperature.

The following experiments have been performed:

- Oxidation and nitridisation of $\mathrm{Zr}$ in high-temperature air and nitrogen were investigated in the CLadding oxidation in high-temperature AIR (CLAIR) programme at the AEKI.

- Experiments with fission product release in highly oxidising atmosphere, study of Ru oxidation and transport have been started in the RUthenium Separate Effect Tests (RUSET) programme at the AEKI.

- A proposal has been developed for the simulation of integral behaviour of fuel bundles during a severe accident scenario in a SFSP by the AEKI and the QUENCH-10 was executed at the FZK, Karlsruhe.

\section{Cladding oxidation in high-temperature air}

Severe accident scenarios raise the possibility of having hydrogen, air and/or nitrogen around the hot fuel elements. Pure oxygen atmosphere cannot be present in the reactor; however, its study helps to understand the oxidation kinetics. Moreover the former studies were performed mostly with pure zirconium metal, but works regarding zirconium alloys are scarce or entirely missing.

In the CLAIR experiments a resistance-heated vertical tube furnace was used. A quartz inner tube placed into the furnace ensured the controlled atmosphere in the reaction area. At the high-temperature nitrogen experiments the quartz tube had an outer jacket with $10^{-6}$ bar vacuum to avoid oxygen diffusion from outer air to nitrogen above $1000^{\circ} \mathrm{C}$ as suggested by Dravnieks (1950). Streaming gas was used and the flow rates were chosen high enough to avoid starvation in gas mixtures except during the first few seconds. A small quartz sample holder made it possible to insert the sample to the top cold part of the quartz tube and to lower it only after substantial flushing with the reactant gas to the middle section of the hot furnace. At the end of reaction time the sample was pulled back to the upper cold part of quartz inlet tube to cool down. The furnace was continuously kept at the required temperature.

Table 1 shows the type, shape, size, surface area and number of used samples. Tube samples were made of original $\mathrm{Zr} 1 \% \mathrm{Nb}$ and Zircaloy-4 fuel element claddings. The pure zirconium metal samples were disc-shaped cut from rod with $12 \mathrm{~mm}$ diameter and $2 \mathrm{~mm}$ thickness. During the experiments, gas flow rate was $1.33 \mathrm{~cm}^{3} / \mathrm{s}$ and the pressure 1 bar. Before and after the reactions, samples were weighed. 
Table 1 Samples used in CLAIR experiments

\begin{tabular}{llccc}
\hline Sample & Shape & Size $(\mathrm{mm})$ & Surface $\left(\mathrm{mm}^{2}\right)$ & $\begin{array}{c}\text { Number of } \\
\text { samples }\end{array}$ \\
\hline $\mathrm{Zr}$ & Disk & $12 \times 2$ & 3.02 & 3 \\
$\mathrm{Zr} 1 \% \mathrm{Nb}$ & Tube & $9.15 \times 8$ & 4.62 & 45 \\
$\mathrm{Zry}-4$ & Tube & $10.75 \times 8$ & 5.50 & 12 \\
$\mathrm{Zr} 2.5 \% \mathrm{Nb}$ & Plate & $10 \times 10 \times 2$ & 2.80 & 5 \\
\hline
\end{tabular}

The results of air oxidation tests are presented in Figure 1. The AEKI data are compared with earlier studies made in our laboratory and by Andreeva-Andrievskaya et al. (1994) in Bochvar Institute, Moscow. As can be seen, our earlier results are in good agreement with the present data. The results of Andreeva-Andrievskaya et al. are in reasonable agreement even if they were gained by air-steam mixtures with different ratios up to $90 \%$ air content. The results with 50\% and $90 \%$ air content are the same at low oxidation stage and differ only slightly at higher oxidation range. The rate values are from low oxidation stage where the parabolic law is valid and the breakaway effect has not yet appeared.

Figure 1 Air oxidation rate of $\mathrm{Zr} 1 \% \mathrm{Nb}$ and $\mathrm{Zry}-4$

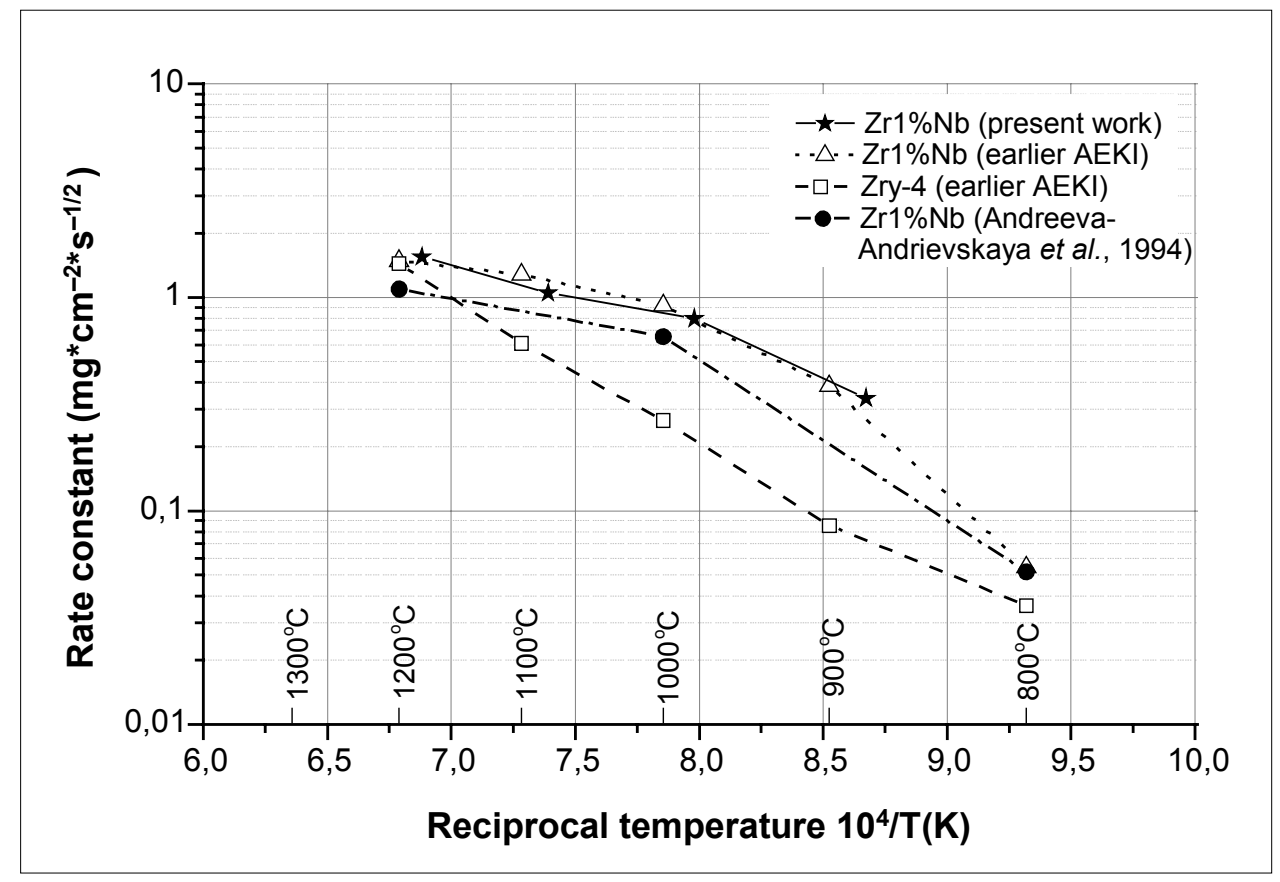

The oxidation of zirconium and different zirconium alloys in pure oxygen gas has been performed. Results are shown in Figure 2. The $\mathrm{Zr} 1 \% \mathrm{Nb}$ oxidation rate constants show a similar character as what appeared at air oxidation; the temperature dependence in Arrhenius plot does not show linear character but increases with a lower rate at higher temperatures. The Zircaloy-4 rate constants are on a straight line, similar to that during 
air oxidation. Pure $\mathrm{Zr}$ metal oxidation rates on Arrhenius plot are linear like those at Zry-4 but with slightly lower absolute values. Our results agree well with the earlier results of Evans et al. (1972) at $1000^{\circ} \mathrm{C}$ and at $1100^{\circ} \mathrm{C}$, but are slightly higher at $900^{\circ} \mathrm{C}$. Evans found lower values, decreased from the linear at Arrhenius plot. Of course the obviously different samples could be the reason for the different behaviour. At larger niobium content $(\mathrm{Zr} 2.5 \% \mathrm{Nb})$ we found an opposite character as at $\mathrm{Zr} 1 \% \mathrm{Nb}$. Cowgill and his co-workers (1968) observed similar trend but with a lower rate for $\mathrm{Zr} 2.7 \% \mathrm{Nb}$ alloy.

Figure 2 Oxidation rate of zirconium and its alloys in oxygen

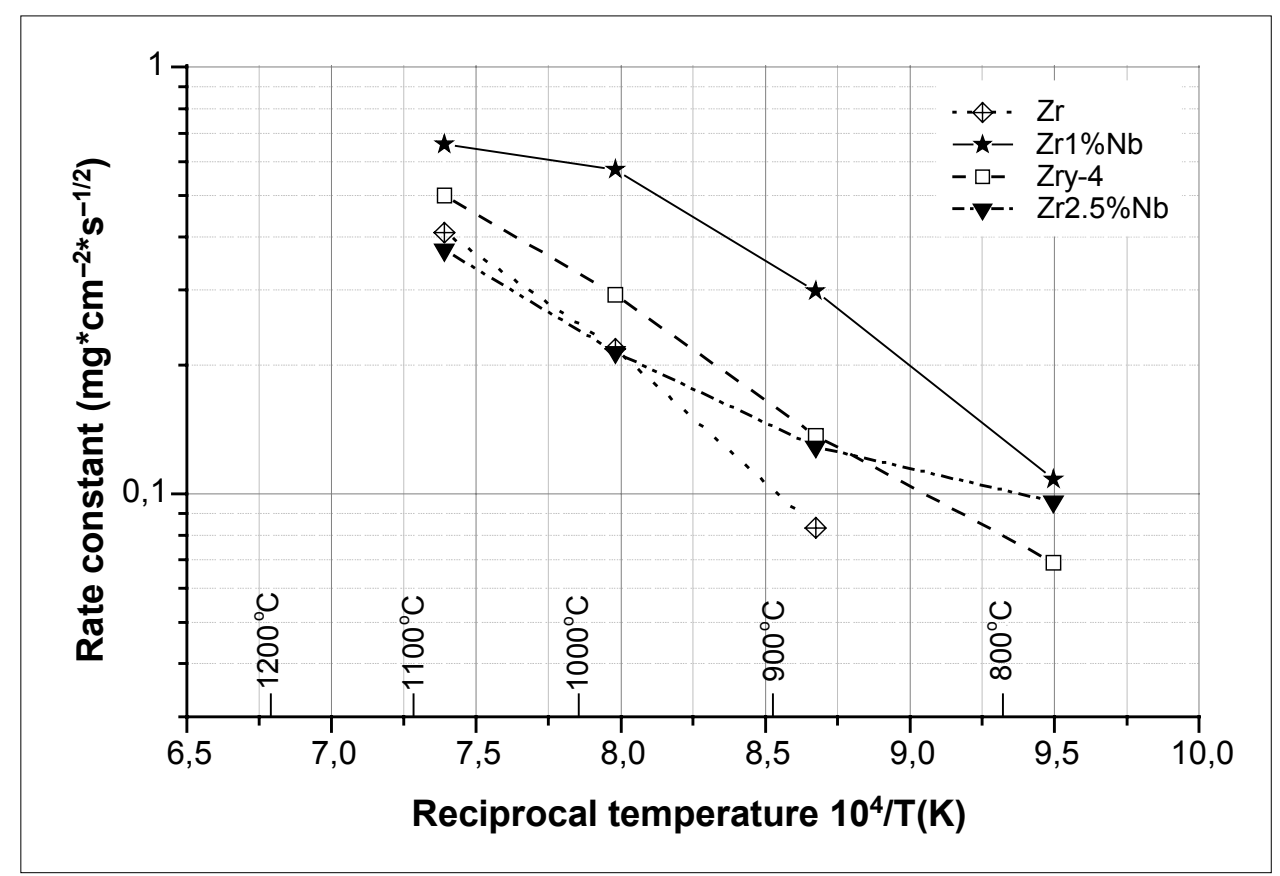

The third series of experiments were performed with $99.995 \%$ purity nitrogen gas. At low extent of reaction, the rate goes according to the parabolic law, maybe above $2 \mathrm{mg} / \mathrm{cm}^{2}$, a breakaway effect started. Low nitrogen take-up interval was chosen, because the samples were intended to be used in ring compression tests. It was clear that only a low extent of oxidation and nitrogen uptake will not lead to high embrittlement. In one temperature $\left(1080^{\circ} \mathrm{C}\right)$ test with Zircaloy-4 PWR cladding tube pieces were carried out with atmospheric pressure nitrogen. The reaction rates again agreed well with those of $\mathrm{Zr}$ (Evans et al., 1972) and Zr1\% Nb (Figure 3).

Based on our experience in ring rupture tests, the nitride layer is so tenaciously adherent to the metal that metal crystals break out together with the nitride scale on their surface.

Figure 4 shows a typical metallographic image of a sample oxidised in air. The oxide scale is porous and consists of oxide-nitride mixture; nitride forms mainly at the phase boundary of metal and oxide. Figure 5 shows the macroscopic appearance of tube segments' reactions in air, oxygen and nitrogen. 
Figure 3 Nitridisation rate of $\mathrm{Zr} 1 \% \mathrm{Nb}$ and $\mathrm{Zry}-4$

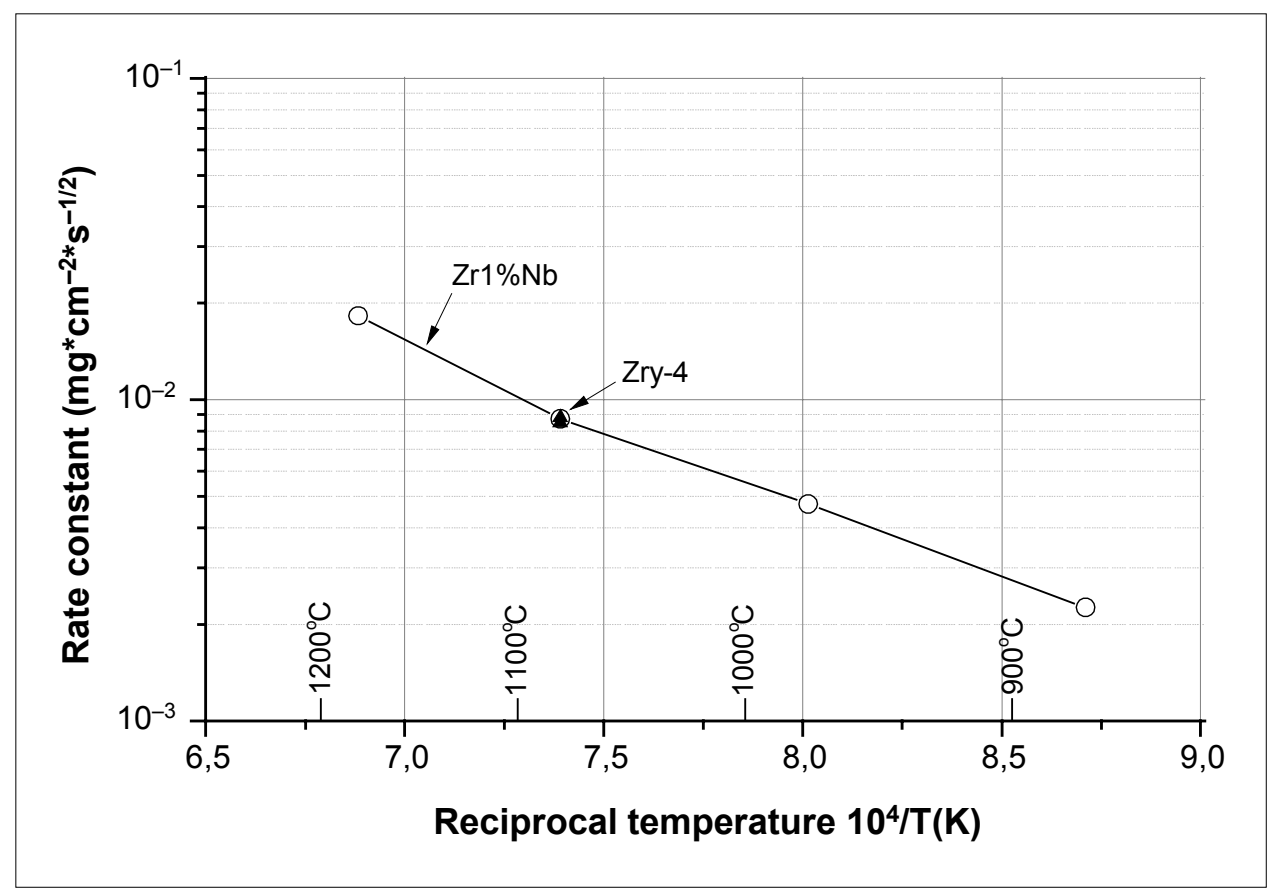

Figure 4 Cross-section of $\mathrm{Zr} 1 \% \mathrm{Nb}$ cladding oxidised at $1080^{\circ} \mathrm{C}$ for $78 \mathrm{~s}$ in air

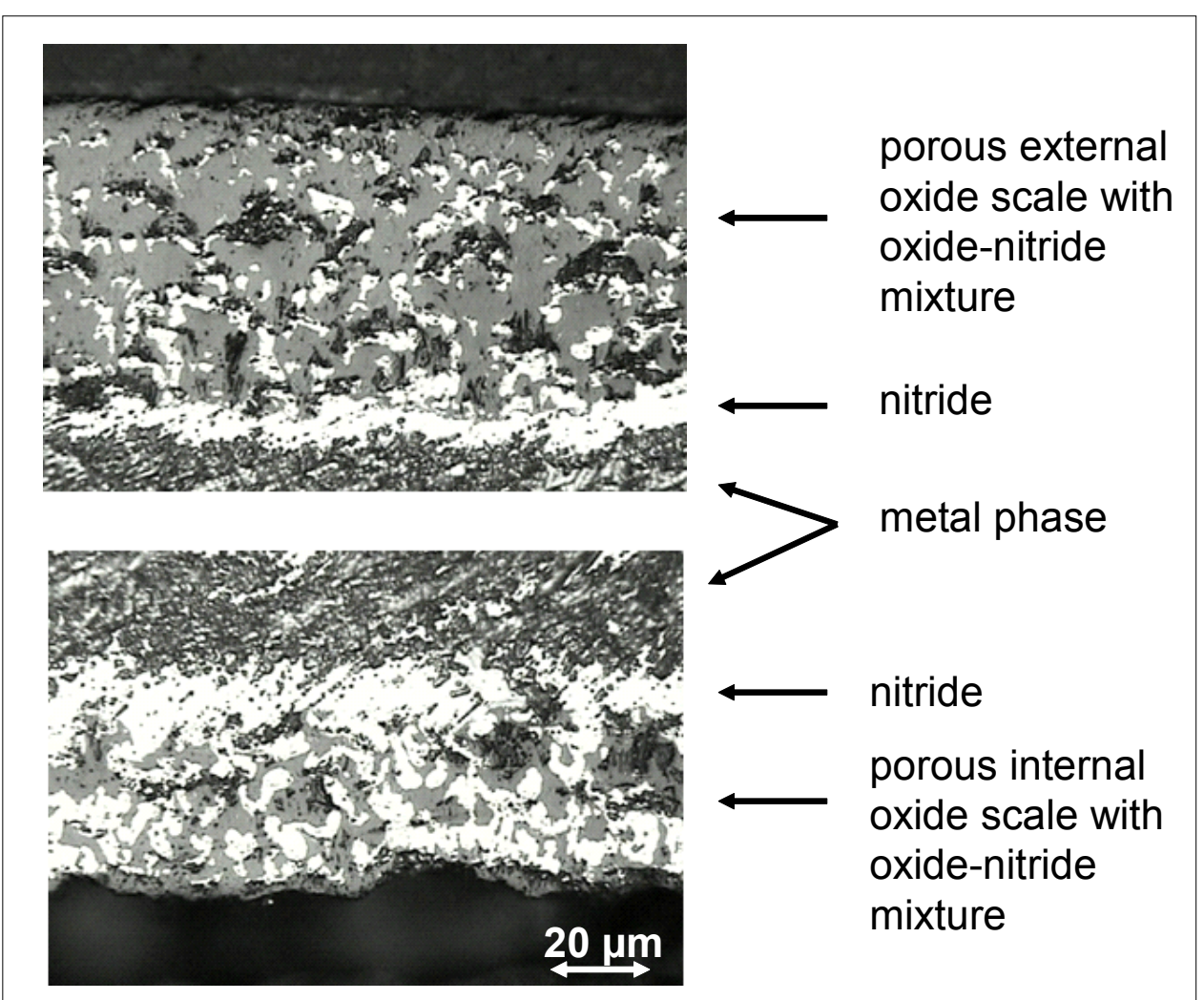


Figure 5 View of oxidised and nitrided cladding samples

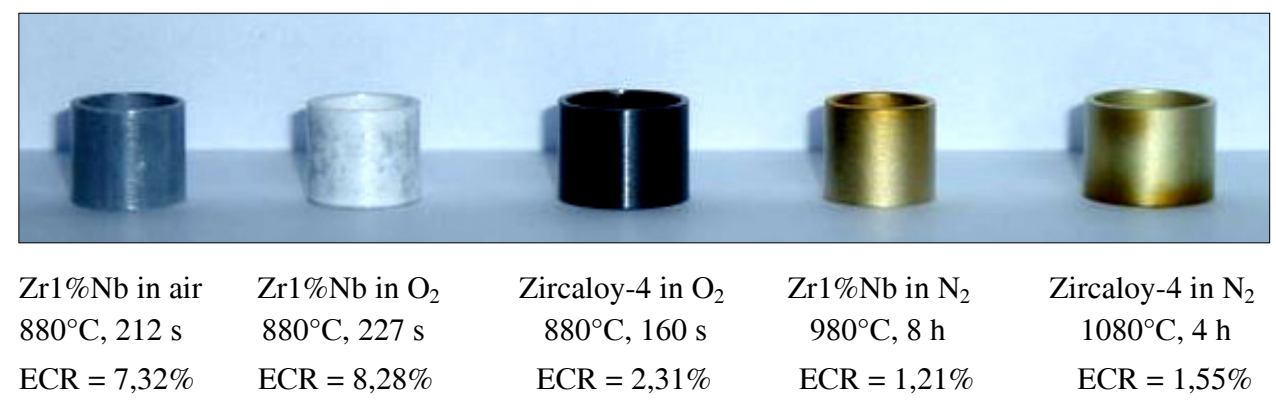

The reaction kinetics of $\mathrm{Zr} 1 \% \mathrm{Nb}$ VVER cladding material have been investigated in air, oxygen and nitrogen at high temperatures $\left(800^{\circ} \mathrm{C}-1200^{\circ} \mathrm{C}\right)$. The $\mathrm{Zr} 1 \% \mathrm{Nb}$ VVER cladding showed a time delay in the start of the reaction process in air and oxygen atmosphere, but not in nitrogen. By comparison, Zircaloy-4 cladding type showed no time delay in the start of oxidation in $\mathrm{O}_{2}$.

The mechanical testing of cladding indicated that samples oxidised in air or oxygen at higher temperature were more brittle than those oxidised at lower temperature at the same ECR values, whereas in the case of nitrogen reaction there were no differences in the brittleness of samples as a function of reaction temperature. Zircaloy-4 showed lower reaction rate in oxygen atmosphere than $\mathrm{Zr} 1 \% \mathrm{Nb}$, but at the same ECR values a more brittle behaviour has been found.

\section{Oxidation and release of ruthenium in high-temperature air}

The RUSET experiments investigate the release of ruthenium and other fission products in the presence of high-temperature air. The current test programme include two series of experiments:

1 Powder tests with pure metallic $\mathrm{Ru}$, with non-active fission product components dispersed as well in $\mathrm{ZrO}_{2}$ or $\mathrm{UO}_{2}$ powder; they were conducted at constant temperature set between $1000^{\circ} \mathrm{C}$ and $1200^{\circ} \mathrm{C}$. The released $\mathrm{Ru}$ was collected and the amount of precipitated $\mathrm{RuO}_{2}$ and concentration of $\mathrm{RuO}_{4}$ in the escaping ambient temperature air were determined.

2 Tests on short fuel rod segments containing compacted fuel pellets with non-active fission product elements. The applied temperature ranged between $1300^{\circ} \mathrm{C}$ and $1800^{\circ} \mathrm{C}$. These experiments provided information on the retention of fission products by the fuel rod.

The first series of experiments was carried out with fission product components mixed in $\mathrm{ZrO}_{2}$ powder. The samples contained the characteristic fission products, including both volatile and non-volatile components (Ru, Mo, Cs, I, Ba, Se, Sn, Ag, Sb, Cd, Te, $\mathrm{Nd}, \mathrm{Ce}$ and $\mathrm{Zr}$ ) and were prepared as a mixture of powder components. During the tests, the air injection started only when the furnace and the sample were heated up to the 
required target temperature. The quartz tube outlet was connected to a gas sampling device (Figure 6). The gas supply system providing constant gas flow was connected to the furnace inlet. During the experiments, the released gaseous $\mathrm{Ru}$ was collected in two places in order to determine the amount of gaseous $\left(\mathrm{RuO}_{4}\right)$ and precipitated $\left(\mathrm{RuO}_{2}\right)$ components:

1 at the area of precipitation, where an inner quartz tube was placed into the reaction chamber outlet tube. The mass of precipitations was measured by weighing the quartz tube before and after the experiments.

2 the gaseous ruthenium oxide components were absorbed in a bubbler filled with $1 \mathrm{n}$ $\mathrm{HCl}$ solution.

The short fuel rod samples consisted of one or two fuel pellets enclosed in $\mathrm{Zr}$ cladding. Most of the pellets were fabricated for these experiments and contained inactive fission product simulant materials. In some cases, original, fresh pellets were used and the Fission Products (FP) were added into the gap between the pellet and cladding. The pellets have been prepared from the mixture of $\mathrm{UO}_{2}, \mathrm{Ru}$ and other fission products powder compacted at high pressure. An inductively heated furnace was used to conduct short fuel rod tests. The maximum temperature in the furnace was above $1800^{\circ} \mathrm{C}$ which is much higher than in the case of powder tests. The outlet junction of the furnace was connected to the sampling system. The released ruthenium oxides were collected in two positions similarly to powder test.

Figure 6 Scheme of RUSET experimental facility

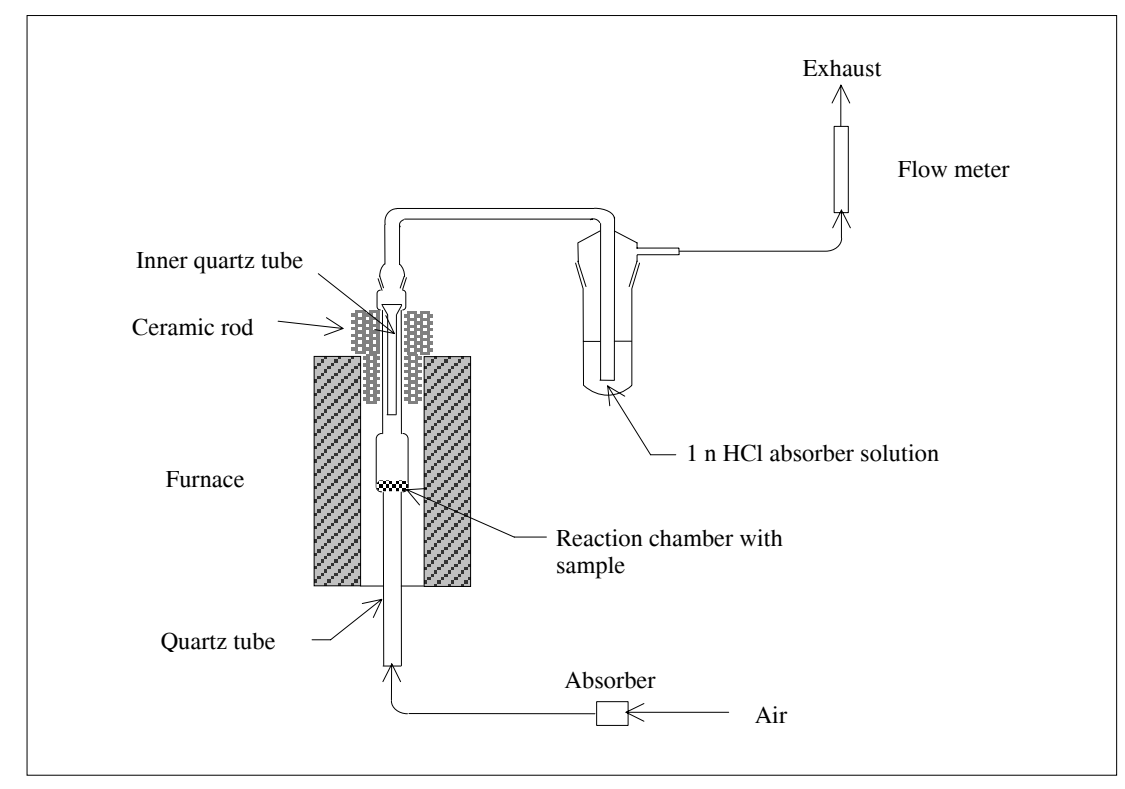


During isothermal oxidation of metallic ruthenium samples, the furnace temperatures were set to a constant value between $1000^{\circ} \mathrm{C}-1800^{\circ} \mathrm{C}$. The air injection into the furnace resulted in the formation of gaseous ruthenium oxides: $\mathrm{RuO}_{3}$ and $\mathrm{RuO}_{4}$.

The outlet section of furnaces simulated the cold surfaces of the primary circuit and the temperature here decreased to $100^{\circ} \mathrm{C}$. At this temperature, the $\mathrm{RuO}_{3}$ decomposed leading to the formation of $\mathrm{RuO}_{2}$ crystals on the cold surfaces; some part of $\mathrm{RuO}_{4}$ also decomposed. When the air from the furnace entering the outlet section was sufficiently hot, $\mathrm{RuO}_{4}$ was produced again through reevaporation of $\mathrm{RuO}_{2}$ deposited on the wall.

A gas bubbler kept at room temperature represented the atmosphere of the containment or the environment. Here the gaseous $\mathrm{RuO}_{4}$ was collected by a chemically reacting solution. Some part of $\mathrm{RuO}_{4}$ was released directly from the furnace, while another part from the outlet section through the reevaporation of deposited $\mathrm{RuO}_{2}$.

The main results of the experiments are related to the identification and determination of gaseous Ru release. Several measurements were made to provide information on the deposition of $\mathrm{Ru}$ and other fission product elements on cold surfaces. The amount of gaseous $\mathrm{Ru}$ oxide release and the amount of $\mathrm{Ru}$ deposits (in the form of $\mathrm{RuO}_{2}$ ) was determined. In most of the powder tests, the sum of elemental ruthenium mass in the released gaseous Ru oxides and the deposits was close to the initial Ru mass placed in the furnace. This means that all metallic Ru was oxidised in these tests.

The main results of the RUSET tests are the following:

- Intense oxidation of metallic Ru can take place in high-temperature air. Gaseous $\mathrm{Ru}$ oxides can be produced and released from SFSP during the late phase of a severe accident.

- The rate of $\mathrm{Ru}$ oxidation is limited by the sum of equilibrium partial pressures of $\mathrm{RuO}_{4}$ and $\mathrm{RuO}_{3}$.

- $\mathrm{RuO}_{2}$ deposits can be formed on the cold surfaces of the reactor hall as a result of the decomposition of $\mathrm{RuO}_{4}$ and $\mathrm{RuO}_{3}$.

- The decomposition of gaseous Ru oxides stops at $600^{\circ} \mathrm{C}-800^{\circ} \mathrm{C}$ and for this reason the partial pressure of gaseous Ru oxides in the reactor hall can be much higher than the equilibrium value (Figure 7). The released $\mathrm{RuO}_{4}$ can reach the environment through the reactor hall.

- Additional $\mathrm{RuO}_{4}$ formation can be expected as a result of the oxidation of $\mathrm{RuO}_{2}$ deposits in high-temperature air atmosphere.

- The presence of other fission products can delay the release of ruthenium, but does not decrease the released mass.

- The most important factor in the retention of ruthenium release in high-temperature air is the integrity of fuel rod cladding. 
Figure 7 The partial pressure of volatile $\mathrm{Ru}$ oxides as a function of reciprocal temperature

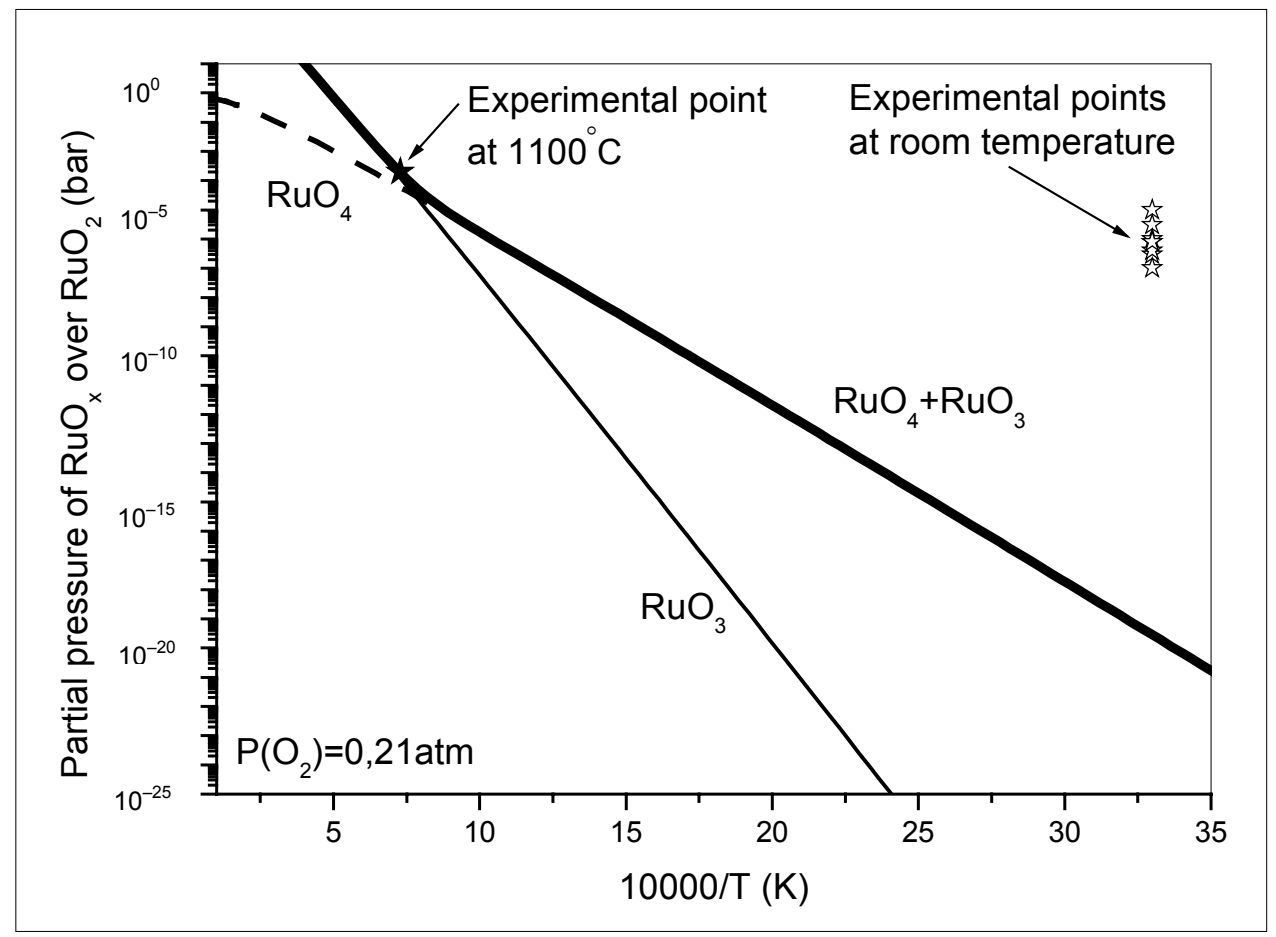

Notes: The lines show the equilibrium partial pressures; the symbols refer to the values measured in the tests.

\section{Integral bundle test in high-temperature air}

The integral behaviour of fuel bundles in high-temperature air has been investigated in the CODEX-AIT-1 and CODEX-AIT-2 tests several years ago (Hózer et al., 2003). The very intense oxidation of zirconium components and the formation of zirconium nitrides in the high-temperature phase of the accident were demonstrated. The tests indicated the release of uranium oxides proportional to the partial pressures of the oxides in the given atmosphere. However, the CODEX-AIT tests were specified on the basis of classical reactor accidents and simulated the behaviour of fuel rods in the core periphery after the failure of the lower head and penetration of air into the reactor vessel from the bottom. The scenario of a severe accident in the SFSP is rather different from the reactor case. For this reason AEKI proposed to carry out new air ingress tests on the QUENCH facility in Karlsruhe. This proposal has been accepted and approved in the framework of the EU LACOMERA project and the test QUENCH-10 was based on the scenario specified for the severe SFSP accident. There were two important aspects that had to be taken into account during the preparation of the tests:

1 The severe SFSP accident starts from a water pool and the air ingress phase takes place only after the evaporation of the full water volume. This rather long evaporation phase had to be taken into account as a preoxidation phase in high-temperature steam. 
2 The only potential accident management measure to terminate the severe SFSP accident is the injection of water into the fuel rods on the pool. The quenching of high-temperature fuel rods after oxidation in air has never been investigated in integral tests. The information on the quenching phase could be very important for the initiation of accident management measures, since the interaction of oxidised and/or nitrided $\mathrm{Zr}$ with cold water could lead to some chemical reactions.

Test QUENCH-10 was performed in the framework of the EU-supported LACOMERA programme (Miassoedov et al., 2003) proposed by AEKI Budapest, and supported by Paul-Scherrer-Institute, Switzerland (PSI). The main objective of this test was to examine the oxidation and nitride formation of Zircaloy during air ingress, before flooding the bundle with water. The test supported the understanding of the consequences of a possible failure of heat removal in a spent fuel pool.

The test bundle consists of 21 rods, 20 of which were electrically heated over a length of $1024 \mathrm{~mm}$. In QUENCH-10, the central rod was unheated and equipped with additional instrumentation (Schanz et al., 2006; Steinbrück et al., 2006). The Zircaloy-4 rod cladding and the grid spacers are identical to those used in PWR whereas the fuel is represented by $\mathrm{ZrO}_{2}$ pellets.

The main test phases of QUENCH-10 experiment are summarised below and shown in Figure 8:

- $\quad$ stabilisation at $\sim 873 \mathrm{~K}$

- heat-up with $\sim 0.3-0.6 \mathrm{~K} / \mathrm{s}$ to $\sim 1620 \mathrm{~K}$ for $\sim 32 \mathrm{~min}$

- preoxidation in a flow of $3 \mathrm{~g} / \mathrm{s}$ of superheated steam and $3 \mathrm{~g} / \mathrm{s}$ argon for $\sim 113 \mathrm{~min}$ at $\sim 1620-1690 \mathrm{~K}$

- intermediate cooling from $\sim 1690 \mathrm{~K}$ to $1190 \mathrm{~K}$ in a flow of $3 \mathrm{~g} / \mathrm{s}$ of superheated steam and $3 \mathrm{~g} / \mathrm{s}$ argon for $\sim 38 \mathrm{~min}$

- air ingress during transient heat-up from 1190 to $2200 \mathrm{~K}$ with an initial heating rate of $\sim 0.3 \mathrm{~K} / \mathrm{s}$ in a flow of $1 \mathrm{~g} / \mathrm{s}$ of air for $\sim 30$ min (superheated steam flow turned off, Ar flow kept constant)

- Quenching the bundle by water injection rate of $50 \mathrm{~g} / \mathrm{s}$.

At the onset of the air ingress phase the change in flow from steam to air had the immediate effect of reducing the heat transfer from the bundle so that the temperatures began to rise (see turnaround in temperature at $11629 \mathrm{~s}$ in Figure 8). The temperature increase was intensified by raising the electrical power so that the bundle temperature reached the target of $2073 \mathrm{~K}$. Complete consumption of oxygen and partial consumption of nitrogen were observed towards the end of the air ingress phase (Figure 9). During the oxygen starvation about $0.3 \mathrm{~g}$ of hydrogen were released. About $3.5 \mathrm{~g}$ nitrogen, previously taken up by the formation of $\mathrm{ZrN}$ was released at the beginning of the quench phase, indicating the reoxidation of $44 \%$ zirconium nitride during flooding. 
Figure 8 Temperature at the $950 \mathrm{~mm}$ level and electric power versus time together with designations of the QUENCH-10 test phases



Figure 9 Off-gas composition during the air ingress phase of QUENCH-10




The post-test inspection showed an extremely oxidised (degraded) bundle in the hot region, i.e., between $750 \mathrm{~mm}$ and $1000 \mathrm{~mm}$ (Figure 10 left). An inspection by videoscope revealed local oxide scale degradation of $\mathrm{Zr}$ cladding and shroud, which is connected with oxide scale bulging and spalling as well as the formation of zirconium nitride phases within the sublayers of the inner scale, e.g., at the inner shroud surface between $400 \mathrm{~mm}$ and $700 \mathrm{~mm}$. The possibility to withdraw during the test allows the reference corner rods to investigate the sequence of oxide layer transformation from one test phase to another (Figure 11). The metallographic investigation of the corner rod, withdrawn during the oxygen starvation period of the air ingress phase, revealed formation of the zirconium nitrides inside the oxide layer. The metallographic investigation of the post-test cladding and shroud structure showed formation of the fragile oxide developed during reflood as a result of the reoxidation of zirconium nitrides. In addition to rubble retained in the bundle (Figure 10 right), large amounts of ceramic particles were carried to the off-gas pipe. The particle size analysis demonstrated that the majority of those particles $\left(95 \% \mathrm{ZrO}_{2}\right)$ had a diameter of $\sim 25 \mu \mathrm{m}$.

The QUENCH bundle experiment on air ingress demonstrated the importance of nitrogen during $\mathrm{Zr}$ oxidation in air leading to severe bundle degradation, i.e., strong cladding and shroud embrittlement and fragmentation in the hot region. The small $\mathrm{H}_{2}$ release in the quench phase compared to experiments with melt formation is the consequence of the especially strong oxidative metal consumption. The quenching phase was accompanied by nitrogen release from the nitrides of the $\mathrm{Zr}$ components.

Figure 10 Post-test appearance of the QUENCH-10 bundle

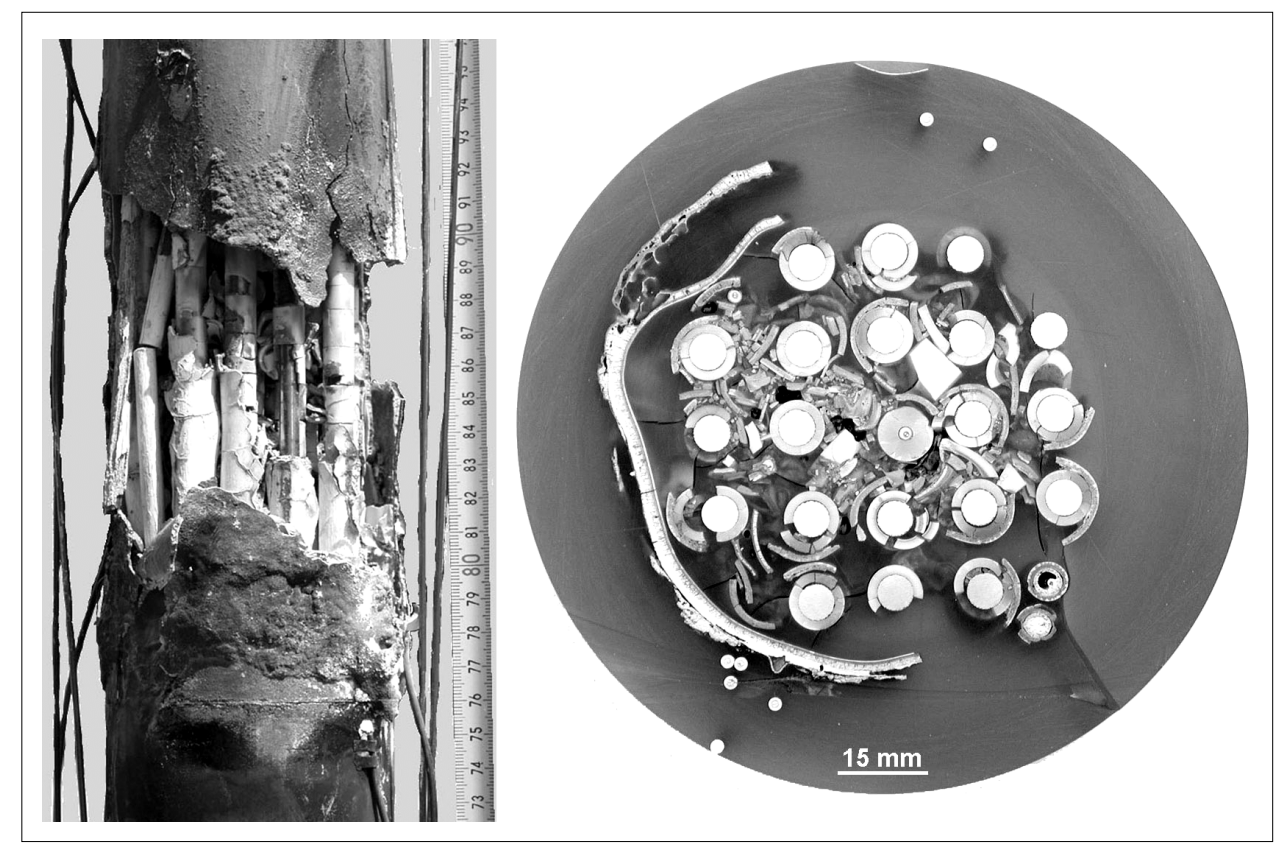


Figure 11 Structural changes of the oxidised Zry-cladding surface during air ingress and quenching of the QUENCH-10 bundle

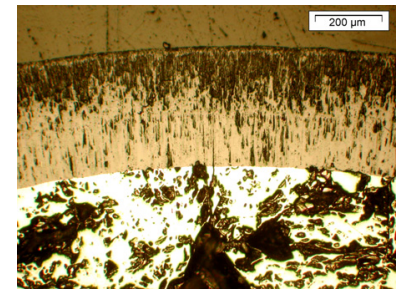

Preoxidised outer surface of the Zry-cladding

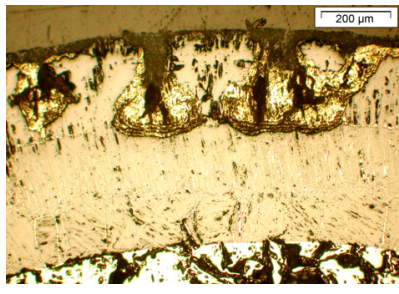

Influence of the air ingress with oxygen starvation conditions: formation of nitride cells inside the $\mathrm{ZrO}_{2}$ oxide layer

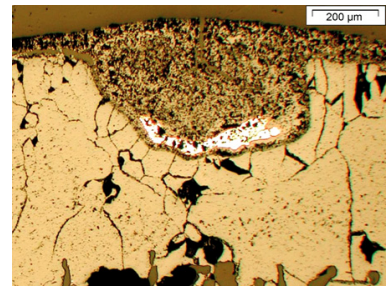

Reconversion of the nitride cells into oxide porous cells

\section{Summary}

The performed high-temperature experiments with fuel materials make possible the development of numerical models for the prediction of the consequences of severe accidents in SFSPs. The results of CLAIR, RUSET and QUENCH-10 experiments carried out in high-temperature air provided important data on the following:

- oxidation kinetics of $\mathrm{Zr}$ alloys in high-temperature air, nitrogen and oxygen

- oxidation kinetics of Ru, release of gaseous Ru oxides and their deposition on cold surfaces

- integral behaviour of fuel rods in severe SFSP accident conditions.

Beyond the scientific value of the experiments, the QUENCH-10 integral test confirmed that water injection can be applied as an accident management measure to terminate accident progression in SFSPs.

\section{References}

Andreeva-Andrievskaya, L.N., Bibilashvili, Y.K., Karpov, V.M., Nechaeva, O.A., Salatov, A.V., Sokolov, N.B., Sotnikov, A.S., Tonkov, V.Y. and Vlasov, F.Y. (1994) 'High temperature interactions of VVER fuel components', International CORA Workshop, 10-12 October, Karlsruhe: KFK.

Cowgill, M.G., Wong, S.H. and Smeltzer, W.W. (1968) 'Breakaway oxidation transition for a zirconium-2.7 w/o niobium alloy', J. Electrochem. Soc., Vol. 115, No. 9, pp.927-929.

Dravnieks, A. (1950) 'The kinetics of the zirconium-nitrogen reaction at high temperatures', J. Am. Chem. Soc., Vol. 72, pp.3568-3571.

Evans, E.B., Tsangarakis, N., Probst, H.B. and Garibotti, N.J. (1972) 'Critical role of nitrogen during high temperature scaling of zirconium', High Temperature Gas-Metal Reactions in Mixed Environments, Boston: Metallurgy Soc. AIME. 
Hózer, Z., Windberg, P., Nagy, I., Maróti, L., Matus, L., Horváth, M., Pintér, A., Balaskó, M., Czitrovszky, A. and Jani, P. (2003) 'Interaction of failed fuel rods under air ingress conditions', Nuclear Technology, Vol. 141, pp.244-256.

Miassoedov, A., et al. (2003) 'Large Scale Experiment on Core Degradation, Melt Retention an Coolability (LACOMERA)', FISA-2003: EU Research in Reactor Safety, Luxembourg, 10-13 November, pp.239-244.

Schanz, G., Heck, M., Hózer, Z., Matus, L., Nage, I., Sepold, L., Stegmaier, U., et al. (2006) 'Results of the QUENCH-10 experiment on air ingress', Report FZKA-7087, Forschungszentrum Karlsruhe.

Steinbrück, M., Miassoedov, A., Schanz, G., Sepold, L., Stegmaier, U. and Stuckert, J. (2006) 'Experiments on air ingress during severe accidents in LWRs', Nucl. Eng. Design, Vol. 236, pp.1709-1719. 